\title{
Sufficient education attainment for a decent standard of living in modern Australia
}

\author{
Emily J. Callander \\ University of Sydney \\ Deborah J. Schofield \\ University of Sydney \\ Rupendra N. Shrestha \\ University of Sydney \\ Simon J. Kelly \\ University of Canberra
}

\begin{abstract}
Education attainment will impact upon an individual's capacity to engage in the labour force, their living standards and hence their poverty status. As such, education should be included in measures of poverty. However, it is not known what a sufficient level of education to have a decent standard of living is. Using the 2003 Survey of Disability, Ageing and Carers different levels of education attainment were tested for their association with labour force participation and income. Based upon this, it was concluded that Year 12 or higher is a sufficient level of education attainment for 15 to 64 year olds; and Year 10 or higher for people over the age of 65 years. This is in line with current government policies to improve Year 12 completion rates. Knowing what a 'sufficient level of education attainment' is, allows education to be included in multidimensional measures of poverty that view education as a key dimension of disadvantage.
\end{abstract}

Keywords: education attainment, labour force participation, living standards 


\section{Introduction}

Multiple international organizations highlight education as a basic right of citizens: the United Nations Children's Fund, UNICEF, sees education as a basis for wellbeing in adulthood, and the Convention on the Rights of the Child speaks of the need for education in meeting children's rights to develop "personality, talents and mental and physical abilities" (United Nations General Assembly 1989). The United Nations (UN) states that primary education is essential for "children to reach their full potential" (UN Department of Public Information 2008: 1), and achieving universal primary education is the focus of the second Millennium Development Goal.

In addition to education being seen as a basic right of all individuals, education has also been associated with a number of specific benefits. These include lower crime levels (Lochner and Moretti 2004), and higher levels of civic engagement and participation (Brehm and Rahn 1997; Bynner and Egerton 2001), both of which are likely to contribute to better living standards for individuals and society. Education is also a key capability that allows an individual to function in modern society and allows individuals to have choices about what sort of a life they may lead (Schultz 1962). It is well documented, for example, that those with higher levels of education are more likely to be employed and more likely to have higher incomes than those with lower levels of education (Kennedy and Hedley 2003; Breusch and Gray 2004; Wilkins 2004; Zhang, Zhao et al. 2006; Laplagne, Glover et al. 2007). It has also been noted that those with higher levels of education have greater freedom in selecting the jobs they would like to be employed in, which allows selection of other valued features such as job security, or increased leisure time (Weisbrod 1962). Thus, education is seen as an essential component of the wellbeing and living standards of individuals and a vital component for participation in modern society.

As education has such an important impact on an individual's living standards, it warrants the inclusion in a poverty measure. This has been argued by Callander, Schofield and Shrestha (2012), who view poverty as low standards of living and have developed a new multidimensional understanding of poverty, whereby poverty status is determined by a number of factors, including education.

While poverty has traditionally only been measured using income (Ambler 1999), incorporating other determinants of living standards is vital for having a robust measure of poverty. The importance of multidimensional poverty measurement has been recognised by key policy makers within Australia. The Commonwealth Department of Family and Community Services (2003) made the statement that poverty should be measured as a multi-dimensional phenomenon; the current Secretary to the Treasury Martin Parkinson supports a multidimensional understanding of wellbeing (Parkinson 2011); and Ken Henry, the former Secretary to the Treasury stated that income measures of poverty and deprivation are too simplistic (Henry 2007). As such, the development of a multidimensional poverty measure for Australia is vital in order for those in multidimensional poverty to be identified. The multidimensional poverty 
measure proposed by Callander, Schofield and Shrestha (2012) views those in poverty as having low income and either poor health or insufficient education attainment.

In order to practically implement such a multidimensional poverty measure, robust indicators of income, health and education need to be identified. As poverty in Australia has traditionally been measured using measures of income (Harding and Szukalska 2000; Harding, Lloyd et al. 2001; Saunders, Hill et al. 2007), the existing methods of measuring income poverty can be adopted. Another study has recently been conducted that assesses robust indicators of poor health (Callander, Schofield et al. 2011). However, it is currently unknown what a sufficient level of education attainment is for contemporary Australian society: one that could be utilised as an indicator of sufficient education in a multidimensional poverty measure. As such, this paper aims to determine what a 'sufficient level of education attainment' is for functioning and participation in modern Australian society. This will be done by undertaking a crosssectional analysis of the nationally representative 2003 Survey of Disability, Ageing and Carers (SDAC) to look at the relationship between different levels of education attainment and one of the most readily accessible measures of social participation labour force participation. This 'sufficient level of education' can then be included in any multidimensional poverty measure that has education as a component.

\section{Methods}

The 2003 SDAC was used in this study; this is a nationally representative survey of the Australian population (it includes those who have a disability and those who do not have a disability), conducted by the Australian Bureau of Statistics (ABS). It meets the needs of this study by including detailed measures of education attainment and labour force participation.

The 2003 SDAC covered individuals in all states and territories of Australia however, those in very remote areas were excluded. The survey covered both private and non-private dwellings, excluding gaols and correctional institutions. The ABS selected households at random using multistage sampling techniques and surveyed every individual within the household. There were 36241 respondents in 14019 households, and 5145 individuals from 303 non private dwellings and 564 careaccommodation establishments. The response rate for those in private and non private dwellings was $89 \%$, and for those in care-accommodation $90 \%$ (Australian Bureau of Statistics 2005). The original 2003 SDAC data was weighted by the ABS to represent the whole Australian population in 2003 by age, sex, state/territory, and section of state characteristics.

\section{Statistical Analysis}

The analysis for determining what a sufficient level of education attainment is for participating in the labour force was only conducted for persons between the ages of 15 years to 64 years, living in households. For those over the age of 65 (that is, over 
retirement age) looking at labour force status is not always relevant. For this age group a separate analysis was undertaken to look at the distribution of income for those with different levels of highest education attainment. Thus, for those aged 15 to 64 years, this study assessed the levels of highest education attainment that were associated with a higher chance of labour force participation. For those aged 65 years and over, this study assessed the levels of highest education attainment that were associated with having a higher income.

Chi-squared analysis and regression models were conducted using SAS 9.2 to identify the variation in labour force participation associated with differing levels of highest education attainment for 15 to 64 year olds. Labour force participation categories were divided into - employed and not employed. Those who were defined as 'employed' were in either full time or part-time employment. Those who were defined as not employed where either unemployed and looking for full-time or part time employment, or were not in the labour force. The results, where appropriate, were controlled for the impact of age and gender. Controlling for age is seen to be particularly important as the levels of education attainment have risen over time - within the two decades from 1981 to 2001 , for example, the number of individuals obtaining a higher education doubled for males and increased five-fold for females (Productivity Commission 2005).

For those aged 65 years and over, chi-squared analysis and regression models were conducted to identify the variation in total income received with differing levels of highest education attainment. Total income consisted of private and transfer income, and was divided by the ABS into 10 groups. The results, where appropriate, were controlled for the impact of age and gender.

Ethics approval for this study was obtained from the University of Sydney Human Ethics Committee.

\section{Results}

From the 2003 SDAC, of the people who were aged between 15 and 64 years in the Australian population and were living in households, the most common level of highest education attainment was an Advanced Diploma/Certificate IV/Certificate III (held by $28 \%$ of people) (Table 1). This was followed by Year $12(18 \%)$, then Year $10(15 \%)$ and a Bachelor degree (14\%). Only $5 \%$ of people had a postgraduate degree; and $5 \%$ also had Year 8 or below their highest level of education attainment. 
Table 1: Highest level of education attainment for Australians aged 15-64 years, living in households in 2003

\begin{tabular}{lcc}
\hline $\begin{array}{l}\text { Highest level of education } \\
\text { attainment }\end{array}$ & Numbers & $\begin{array}{c}\text { \% of population aged 15 - 64 } \\
\text { years }\end{array}$ \\
\hline Postgraduate degree & 640676 & 5 \\
Bachelors degree & 1840724 & 14 \\
Advanced diploma, Certificate & 3746389 & 28 \\
IV, Certificate III & & \\
Certificate II, Certificate I, other & 83040 & 1 \\
Certificate & & \\
Year 12 & 2363826 & 18 \\
Year 11 & 979168 & 7 \\
Year 10 & 2027519 & 15 \\
Year 9 & 884503 & 7 \\
Year 8 or below & 714810 & 5 \\
\hline
\end{tabular}

The group whose highest level of education attainment was a postgraduate degree had the highest proportion of individuals in employment (86\%) - followed closely by those with a Bachelors degree (85\%), and those with a Advanced Diploma/Certificate IV/Certificate III (81\%) and Year 12 (75\%)(Table 2). Those with a Certificate II, Certificate I, or other Certificate had the highest proportion of individuals unemployed. Around half of the people with Year 8 or below and Year 9 as their highest level of education attainment were not in the labour force.

Table 2: Labour force status by highest level of education attainment for those aged 15 to 64 years, living in households in 2003

\begin{tabular}{lcccc}
\hline $\begin{array}{l}\text { Highest level of } \\
\text { education } \\
\text { attainment }\end{array}$ & $\begin{array}{c}\text { Employed full } \\
\text { time (\%) }\end{array}$ & $\begin{array}{c}\text { Employed part } \\
\text { time (\%) }\end{array}$ & $\begin{array}{c}\text { Unemployed } \\
\text { (looking for } \\
\text { work) (\%) }\end{array}$ & $\begin{array}{c}\text { Not in the labour } \\
\text { force (\%) }\end{array}$ \\
\hline $\begin{array}{l}\text { Postgraduate } \\
\text { degree }\end{array}$ & 66 & 20 & 2 & 11 \\
$\begin{array}{l}\text { Bachelors degree } \\
\text { Advanced }\end{array}$ & 65 & 20 & 3 & 12 \\
diploma, & 61 & 20 & 3 & 16 \\
Certificate IV, & & & & \\
Certificate III & & & & \\
Certificate II, & 34 & 26 & 12 & \\
Certificate I, other & & & & \\
Certificate & 48 & 27 & 5 & 20 \\
Year 12 & 40 & 25 & 5 & 30 \\
Year 11 & 23 & 6 & 30 \\
Year 10 & 20 & 6 & 59 \\
Year 9 & 25 & 11 & 5 & \\
Year 8 or below & 25 & & & \\
\hline
\end{tabular}


After controlling for age and sex there was no significant difference in the likelihood of being employed (full time or part time) for those with a Bachelors degree, compared to those with a postgraduate degree (OR 0.97, $p=0.7898$ ) (Table 3). All individuals with other levels of highest education had significantly lower odds of being employed compared to those with a postgraduate degree - see Table 3. Table 3 also shows that the likelihood of being employed declines with the following order of highest education attainment (when compared to those with a postgraduate degree and adjusted for age and sex): Bachelors degree, Advanced Diploma/Certificate IV/Certificate III, Year 12, Year 11, Year 10, Certificate II/Certificate I/other Certificate, Year 9, Year 8 or below.

People whose highest level of education attainment was an Advanced Diploma/Certificate IV/Certificate III were 33\% less likely (OR 0.67, 95\% Cl: $0.56-0.80$ ), and those with Year 12 were $51 \%$ less likely (OR $0.49,95 \% \mathrm{Cl}: 0.41-0.59$ ), to be employed than those with a postgraduate degree, controlling for age and sex. People whose highest level of education attainment was Year 9 were $87 \%$ less likely (OR 0.13 , $95 \% \mathrm{Cl}: 0.11-0.16$ ), and those with Year 8 or below were $91 \%$ (OR 0.09, 95\% Cl: 0.07 -0.11 ) less likely to be employed than those with a postgraduate degree.

Table 3: OR of being employed (full time or part time) compared to people with a postgraduate degree as their highest level of education attainment, controlling for age and sex

\begin{tabular}{lccc}
\hline Degree & OR & $\mathbf{9 5 \%} \mathbf{C l}$ & p-value \\
\hline Postgraduate & REFERENCE & REFERENCE & \\
Bachelor & 0.97 & 0.80 to 1.19 & 0.7898 \\
Adv. Dip./Dip./Cert IV/Cert III & 0.67 & 0.56 to 0.80 & $<.0001$ \\
Cert II/I, other & 0.27 & 0.18 to 0.40 & $<.0001$ \\
Yr 12 & 0.49 & 0.41 to 0.59 & $<.0001$ \\
Yr 11 & 0.30 & 0.25 to 0.37 & $<.0001$ \\
Yr 10 & 0.29 & 0.25 to 0.35 & $<.0001$ \\
Yr9 & 0.13 & 0.11 to 0.16 & $<.0001$ \\
Yr 8 or below & 0.09 & 0.07 to 0.11 & $<.0001$ \\
\hline
\end{tabular}

The odds of being employed for people who had Year 11 (OR 0.86 95\%Cl: 0.65 to $1.14 \mathrm{p}=0.2977$ ) or Year 10 (OR $0.8495 \% \mathrm{Cl}$ : 0.64 to $1.103 \mathrm{p}=0.2068$ ) as their highest level of education attainment was not significantly different when compared to people with Certificate II, Certificate I, or other Certificates as their highest level of education, controlling for age and sex (Table 4). 
Table 4: OR of being employed (full time or part time) compared to people with a Certificate II, Certificate I or their certificate as their highest level of education attainment, controlling for age and sex

\begin{tabular}{lccc}
\hline Degree & OR & $\mathbf{9 5 \%} \mathbf{C l}$ & p-value \\
\hline Postgraduate & 3.14 & 2.27 to 4.33 & $<.0001$ \\
Bachelor & 2.77 & 2.08 to 3.68 & $<.0001$ \\
Adv. Dip./Dip./Cert IV/Cert III & 1.91 & 1.45 to 2.51 & $<.0001$ \\
Cert II/I, other & REFERENCE & REFERENCE & \\
Yr 12 & 1.39 & 1.06 to 1.84 & 0.0190 \\
Yr 11 & 0.86 & 0.65 to 1.14 & 0.2977 \\
Yr 10 & 0.84 & 0.64 to 1.10 & 0.2068 \\
Yr 9 & 0.37 & 0.28 to 0.49 & $<.0001$ \\
Yr 8 or below & 0.26 & 0.19 to 0.34 & $<.0001$ \\
\hline
\end{tabular}

People with Year 12, Advanced Diploma/Certificate IV/Certificate III, Year 9 and Year 8 or below as their highest level of education attainment, had significantly different odds of being employed when compared to people with all other levels of highest education attainment. This is also true for people with a Bachelors degree, who had significantly different odds of being employed compared to all others with different levels of highest education attainment - with the exception of people with a postgraduate degree.

\section{Sufficient education for those aged over 65 years}

Of those who were aged over 65 years and were living in households in 2003, the majority had Year 8 or below as their highest level of education, followed by a Certificate IV, or Certificate III then Year 10 and Year 9 as their highest level of education attainment (Table 5). Only $2 \%$ had a postgraduate degree, $7 \%$ had a Bachelor degree, and only $4 \%$ had Year 12 as their highest qualifications.

Table 5: Highest level of education attainment for those aged 65 years and over

\begin{tabular}{lcc}
\hline Highest level of education attainment & $\begin{array}{c}\text { Number in } \\
\text { population }\end{array}$ & $\%$ \\
\hline Post graduate & 37500 & 2 \\
Bachelor & 151300 & 7 \\
Advanced Diploma & 144100 & 7 \\
Certificate IV/ Certificate III & 407000 & 18 \\
Certificate II, Certificate I, other Certificate & 5000 & 0 \\
Year 12 & 96900 & 4 \\
Year 11 & 56500 & 3 \\
Year 10 & 296600 & 13 \\
Year 9 & 249400 & 11 \\
Year 8 or below & 751800 & 34 \\
\hline
\end{tabular}


Table 6 shows for each level of highest education attainment, the proportion of individuals with different ranges of total weekly income. People with a postgraduate degree, Bachelor degree, Year 12 and Advanced Diploma had the highest proportion of individuals with the highest weekly income. People with Year 10, Year 9 or Year 8 or below education had the highest proportion of individuals in the lowest three groups of income, and the lowest proportion in the highest three groups.

Table 6: Proportion of individuals in each level of highest education with different weekly income ranges

\begin{tabular}{|c|c|c|c|c|c|c|c|c|c|c|}
\hline $\begin{array}{l}\text { Highest level of } \\
\text { education } \\
\text { attainment } \\
\end{array}$ & $\begin{array}{l}\$ 129 \\
\text { or } \\
\text { less }\end{array}$ & $\begin{array}{l}\$ 130 \\
- \\
\$ 186\end{array}$ & $\begin{array}{l}\$ 187 \\
- \\
\$ 224 \\
\end{array}$ & $\begin{array}{l}\$ 225 \\
- \\
\$ 319 \\
\end{array}$ & $\begin{array}{l}\$ 320 \\
- \\
\$ 449\end{array}$ & $\begin{array}{l}\$ 450 \\
- \\
\$ 574\end{array}$ & $\begin{array}{l}\$ 575 \\
- \\
\$ 701 \\
\end{array}$ & $\begin{array}{l}\$ 702 \\
- \\
\$ 881\end{array}$ & $\begin{array}{c}\$ 882 \\
- \\
\$ 1150 \\
\end{array}$ & $\$ 1151+$ \\
\hline Post graduate & $3 \%$ & $18 \%$ & $9 \%$ & $12 \%$ & $5 \%$ & $7 \%$ & $10 \%$ & $7 \%$ & $7 \%$ & $22 \%$ \\
\hline Bachelor & $6 \%$ & $9 \%$ & $14 \%$ & $15 \%$ & $12 \%$ & $7 \%$ & $10 \%$ & $11 \%$ & $4 \%$ & $12 \%$ \\
\hline Advanced Diploma & $5 \%$ & $14 \%$ & $17 \%$ & $18 \%$ & $14 \%$ & $9 \%$ & $10 \%$ & $4 \%$ & $5 \%$ & $5 \%$ \\
\hline $\begin{array}{l}\text { Certificate IV/ } \\
\text { Certificate III }\end{array}$ & $5 \%$ & $23 \%$ & $25 \%$ & $22 \%$ & $10 \%$ & $6 \%$ & $4 \%$ & $2 \%$ & $1 \%$ & $2 \%$ \\
\hline $\begin{array}{l}\text { Certificate II, } \\
\text { Certificate I, other } \\
\text { Certificate }\end{array}$ & $15 \%$ & $0 \%$ & $12 \%$ & $31 \%$ & $6 \%$ & $0 \%$ & $35 \%$ & $0 \%$ & $0 \%$ & $0 \%$ \\
\hline Year 12 & $9 \%$ & $15 \%$ & $25 \%$ & $24 \%$ & $10 \%$ & $1 \%$ & $6 \%$ & $3 \%$ & $2 \%$ & $6 \%$ \\
\hline Year 11 & $10 \%$ & $20 \%$ & $19 \%$ & $26 \%$ & $7 \%$ & $5 \%$ & $6 \%$ & $3 \%$ & $1 \%$ & $3 \%$ \\
\hline Year 10 & $10 \%$ & $20 \%$ & $31 \%$ & $22 \%$ & $7 \%$ & $3 \%$ & $4 \%$ & $1 \%$ & $0 \%$ & $2 \%$ \\
\hline Year 9 & $9 \%$ & $23 \%$ & $32 \%$ & $20 \%$ & $9 \%$ & $4 \%$ & $2 \%$ & $0 \%$ & $0 \%$ & $1 \%$ \\
\hline Year 8 or below & $6 \%$ & $30 \%$ & $33 \%$ & $21 \%$ & $5 \%$ & $2 \%$ & $1 \%$ & $1 \%$ & $0 \%$ & $1 \%$ \\
\hline
\end{tabular}

\section{Discussion}

The results show the different rates of labour force participation, and financial outcomes for a variety of education levels. The aim of this study was to determine what a 'sufficient level of education attainment' is, that will allow people to participate fully in society. Older age groups generally had lower levels of education attainment. Based upon the high proportion of individuals in the lowest weekly income groups, Year 9, and Year 8 or below as highest levels of education attainment can be seen to give individuals aged 65 years and over inadequate education capabilities. In order to be classified as having a 'sufficient level of education attainment', people aged 65 years and over must have completed Year 10 or a higher level of education.

For the current workforce - people aged 15 to 64 years - having a tertiary education (postgraduate or bachelor degree) left individuals with drastically higher chances of being employed. Those with a Year 12 education had around half the odds of being employed as those with a tertiary education. Those with Year 11, Year 10 and Certificate II/Certificate I/other certificate education had around one third the chance of being employed compared to those with a tertiary education; and those with Year 9 or Year 8 and below had around one tenth the chance of being employed. 
From this it may be concluded that having at least a Year 12 education (Year 12, Advanced Diploma/Certificate IV/Certificate III, Bachelor degree, postgraduate degree) will give individuals a decent chance of being employed, and this may be seen as a sufficient level of education attainment for Australians of working-age.

This finding - that Year 12 or a higher level of education is a sufficient level of education attainment - is supported by current Australian policy regarding education attainment and employment. The Council of Australian Government's National Education Agreement focuses on Year 12 education. The agreement aims to ensure that Australian students obtain "knowledge and skills to participate effectively in society and employment" (COAG Reform Council 2009: xv). The agreement states that Year 12 attainment is an indicator of successful transitions from schooling to work or further study (COAG Reform Council 2009).

Furthermore, Year 12 is also vital in order for individuals to have the option of whether to pursue higher education. The current Commonwealth government has set a target, that by $202540 \%$ of Australians aged 25 to 34 years should hold a Bachelor degree (Bradley 2008). However, it is estimated that currently between 45,000 and 50,000 young Australians exit schooling early, that is, before the completion of Year 12 (Access Economics 2005). These individuals may be significantly disadvantaged in the future as they will not have the benefits that higher levels of education can provide, and higher education is also becoming more valued within society.

Individuals must have the skills and education which are valued in society, or produce products which are highly valued in society. Such a situation is being illustrated within Australia with the shift away from low skill industries, to a more professionalised economy (Productivity Commission 2005). In the past, lower levels of education attainment were more common - as evident by the results in this study showing the high proportion of people aged 65 years and over with Year 8 or below as their highest level of education attainment. This lower level of education attainment in previous times was sufficient as low skilled jobs were more common (Community Affairs Reference Committee 2004).

Employers are now demanding an increased education and skill base from their workers as standard (Community Affairs Reference Committee 2004). Low skill jobs are becoming increasingly scarce, with skilled positions now making up 58\% of all positions in Australia in 2000 (Community Affairs Reference Committee 2004). Over 95\% of newly created jobs throughout Australia were filled by people with "skills and a university degree, a diploma or equivalent work experience" (Australian Council of Social Service 2008) in 2004. This indicates that there will be fewer jobs and more competition for those with lower education - this is supported by the results of this study which show that those with a postgraduate degree, Bachelor degree or Advanced Diploma/Certificate IV/Certificate III have a much higher chance of being employed than those with other levels of education.

The recent closure of manufacturing plants has also brought attention to the importance of re-skilling and education for existing workers (Hoy 2007; Burrow 2009; 
Camillo 2009; Unknown 2009). Those with a higher level of education are more likely to be able to adjust to changing job requirements and acquire new skills (Weisbrod 1962; Productivity Commission 2005). Those with little schooling will be particularly affected by shifts away from manual, low skilled jobs as not only are these jobs disproportionately held by those with lower education, but these people will be less able to adjust and reskill (Productivity Commission 2005).

Any growth that has occurred in low skilled/education occupations has been for part time or casual roles (Australian Council of Social Service 2007). The Productivity Commission found that for people who moved out of unemployment into casual work, in the following twelve months half remained in only a casual position and did not progress into more stable full time work, and $27 \%$ returned to unemployment. These people were also likely to have lower education (Productivity Commission 2006). Casual roles are characterised as having poor job security for their workers, fewer entitlements such as paid leave, and often have rates of pay similar to that of welfare payments (ACT Council of Social Service 2006). This highlights the importance of education for not only gaining employment in general, but for also having the freedom to select a job that provides financial security and lifestyle flexibility.

Other studies have looked at the relationship between education attainment and labour force participation and, predictably, all have reported similar findings - that labour force participation increases with higher levels of education attainment (Kennedy, Stoney et al. ; Kennedy and Hedley 2003; Breusch and Gray 2004; Wilkins 2004; Zhang, Zhao et al. 2006; Cai 2007; Laplagne, Glover et al. 2007). However, this study can be seen to provide more detailed information on the impacts of different levels of education due to the greater number of education categories used compared to other studies. For example, Kennedy and Hedley (2003) looked at the relationship between labour force participation and education over time from 1981 to 2001. However, the education attainment levels were collapsed into only three groups - "no post school qualifications, non-degree post school qualifications; and degree qualifications" due to limitations of the census data in use (Kennedy and Hedley 2003: 7). It can be argued that so few categories do not reveal all the intricacies in the relationship between different levels of education and labour force participation - and categories such as 'no post high school qualifications' are too broad. Indeed, Kennedy, Stoney and Vance (Kennedy, Stoney et al. 2009) conducted a follow-up study to the Kennedy and Hedley study of 2003 and focused on the labour force participation rates of those with no post-schooling education as it needed more investigation, breaking this group down into three groups: Year 9 and under, Year 10, and Year 11 and 12.

The need for detailed categories of education attainment is also revealed when looking at the relative impacts of diploma and certificate qualifications and high school education. Laplagne, Glover and Shomos (2007) looked at the impact of education on labour force participation. Education was divided into four categories - Year 11 or lower, Year 12, Certificate or Diploma and degree or higher. It was found that labour force participation increased with higher levels of education and that having a Certificate or 
Diploma had a larger positive impact on the chances of labour force participation compared to those with Year 12 education for women, but a lower impact for men. However other studies have had varying results regarding the impact having a Certificate or Diploma has on labour force participation relative to Year 12 education. Breusch and Gray (2004) found similar results to Laplagne, Glover and Shomos (2007), whereas Wilkins (2004) and Zhang, Zhao and Harris (2006) found that having a Certificate or Diploma has a larger positive impact on labour force participation than Year 12 education. Cai (2007) found the opposite - that having Year 12 education has a greater impact on labour force participation than having a Certificate or Diploma. This study may help to explain these conflicting results by breaking down the education categories in those with an Advanced Diploma/Certificate IV/Certificate III, and those with Certificate II/Certificate I/other Certificates. This study found that these two categories produce significantly different labour force results. Those with Certificate II/Certificate I/other Certificates have less chance of participating in the labour force than those with a Year 12 education, whereas those with Diploma or higher Certificate education have higher chance of participating in the labour force than those with a Year 12 education. This shows the benefit of this study in breaking down highest level of education attainment into more categories than other studies, and the importance of looking at the level of certificate attainment - as gaining a Certificate III or higher significantly increases a individuals chance of labour force participation compared to those who completed a Certificate II or lower. As such, those who complete a Certificate II qualification should be encouraged to continue their studies to increase their chances of labour force participation.

\section{Conclusion}

Knowing what a 'sufficient level of education attainment' is allows education to be included as a dimension of disadvantage in multidimensional measures of poverty. Education is cited as a key capability (Nussbaum 2003; Nussbaum 2006), and similarly having low education attainment if often featured in rhetoric regarding multidimensional poverty measurement (United Nations Development Programme 2008; Social Inclusion Unit 2009; United Nations Development Programme 2010; Alkire and Foster 2011). However, it was previously unknown what a low level of education attainment is for Australian society, and what level of education attainment could be set to divide those with 'high' or 'low', or 'sufficient' or 'insufficient' education attainment.

Internationally, multidimensional poverty measures have included indicators such as completing primary education, and being literate (United Nations Development Programme 2008; World Bank 2008). However, these indicators - which were aimed at assessing poverty status in developing countries are clearly not relevant to Australian society, and thus could not be appropriated into an Australian multidimensional poverty measure. As such, thus study was conducted to determine what an adequate level of education is. 
Having a sufficient level of education is likely to improve the chances of having a decent standard of living by allowing individuals to participate fully in society. Indeed, some level of education is also considered to be part of a decent standard of living in modern society. Education is essential to allow individuals to participate in society, and this study has shown that it is essential to allow individuals to participate in the labour force - a major social institution in modern society.

\section{Note}

' Compared to $38 \%$ in 1980.

\section{References}

Access Economics (2005). The Economic benefit of increased particpation in education and training. Melbourne, Business Council of Australia.

ACT Council of Social Service (2006). Stacking the deck: The impacts of federal employment reforms on the disadvantaged in Canberra. Canberra, ACTCOSS.

Alkire, S. and J. E. Foster (2011). "Counting and multidimensional poverty measurement." Journal of Public Economics 95(7-8): 476-487.

Ambler, J. (1999). Attacking poverty while improving the environment, United Nations Development Program.

Australian Bureau of Statistics (2005). Information Paper - Basic Confidentialised Unit Record File: Survey of Disability, Ageing and Carers 2003 (reissue) Canberra, ABS.

Australian Council of Social Service (2007). The role of further education and training in welfare to work policies. Sydney, ACOSS.

Australian Council of Social Service (2008). Poverty and its causes. Melbourne, The Australian Collaboration.

Bradley, D., Noonan, P., Nugent, H. and Scales, B. (2008). Review of Australian Higher Education: Final Report. Canberra, Commonwealth Department of Education, Employment and Workplace Relations.

Brehm, J. and W. Rahn (1997). "Individual-level evidence for the causes and consequences of social capital." American Journal of Political Science 41: 9991023.

Breusch, T. and E. Gray (2004). Does marriage improve the wages of men and women in Australia? 12th Biennial Conference of the Australian Population Association. Canberra.

Burrow, S. (2009). Re-skilling not redundancy. CareerOne. Online http://www.careerone.com.au/news-advice/work-life/workplace-survival/reskilling-not-redundancy-20090112, CareerOne Pty Ltd.

Bynner, J. and M. Egerton (2001). The wider benefits of higher education. London, Higher Education Funding Council for England.

Cai, L. (2007). The relationship between health and labour force particpation: Evidence from a panel data simultaneous equation model. Melbourne Institute Working Paper Series, no1/07. Melbourne, University of Melbourne.

Callander, E., D. Schofield, et al. (2012). "Towards a holistic understanding of poverty: a new multidimensional poverty measure for Australia." Health Sociology Review 21(2): 138-152. 
Callander, E., D. Schofield, et al. (2011). "Health and functional capacity - capturing capability limitations in measures of health." Health Sociology Review published online DOI: 10.5172/hesr.2012.1624.

Camillo, J. (2009). "Bridgestone closure reveals continuing impacts of the global financial crisis." Australian Manufacturers Workers' Union Retrieved 1 January, 2010, from http://www.amwu.org.au/read-article/news-detail/383/Bridgestoneclosure-reveals-continuing-impacts-of-the-global-financial-crisis/.

COAG Reform Council (2009). National Education Agreement: Baseline performance report for 2008. Sydney, COAG Reform Council.

Commonwealth Department of Family and Community Services (2003). Inquiry into Poverty and financial hardship. Commonwealth Department of Family and Community Services.

Community Affairs Reference Committee (2004). A hand up not a hand out: Renewing the fight against poverty. Senate Inquiry into Poverty 2004. Canberra, The Senate.

Harding, A., R. Lloyd, et al. (2001). Financial disadvantage in Australia 1990 to 2000: The persistence of poverty in a decade of growth. Camperdown, The Smith Family.

Harding, A. and A. Szukalska (2000). Financial disadvantage in Australia - 1999: The unlucky Australians. Camperdown The Smith Family.

Henry, K. (2007). Addressing extreme disadvantage through investment in capability development. Closing Address. Australian Institute of Health and Welfare Conference 'Australia's Welfare 2007'. Canberra.

Hoy, G. (2007). Auto unions, Labor attack Govt over Ford job losses. The 7.30 Report. Australia, Australian Broadcasting Corporation.

Kennedy, S. and D. Hedley (2003). A note on educational attainment and labour force particpation in Australia. Treasury Working Paper 2003-03. Canberra, Australian Treasury.

Kennedy, S., N. Stoney, et al. (2009). "Labour force participation and the influence of education attainment." Economic Roundup (3): 19-36.

Laplagne, P., M. Glover, et al. (2007). Effects of health and education on labour force particpation. Canberra, Productivity Commission.

Lochner, L. and E. Moretti (2004). "The effect of education on criminal activity: evidence from prison inmates, arrests and self-reports." American Economic Review 94: 155-189.

Nussbaum, M. C. (2003). "Capabilities as fundamental entitlements: Sen and social justice." Feminist Economics 9: 33-59.

Nussbaum, M. C. (2006). Poverty and human functioning: Capabilities as fundamental rights. Poverty and inequality. D. B. Grusky and S. M. Ravi Kanbur. Stanford, Stanford University Press.

Parkinson, M. (2011). Sustainable Wellbeing - An economic future for Australia. The Shann Memorial Lecture, 23 August 2011.

Productivity Commission (2005). Economic Implications of an Ageing Australia. Research Report. Productivity Commission. Canberra. Canberra, Australian Government.

Productivity Commission (2006). The Role of Non-Traditional Work in the Australian Labour Market. Melbourne, Productivity Commission.

Saunders, P., T. Hill, et al. (2007). Poverty in Australia: Sensitivity analysis and recent trends. Sydney, Social Policy Research Centre, University of New South Wales.

Schultz, T. W. (1962). "Reflections on investment in man." The Journal of Political Economy LXX(5): 1-8. 
Social Inclusion Unit (2009). The Australian Public Service Social Inclusion policy design and delivery toolkit, Department of the Prime Minister and Cabinet. Canberra.

UN Department of Public Information (2008). Goal 2: achieve universal promary education. EndPoverty2015: Make it happen. New York, United Nations.

United Nations Development Programme (2008). Human Development Report 2008. New York, United Nations.

United Nations Development Programme (2010). Human Development Report. New York United Nations Development Programme.

United Nations General Assembly (1989). Covention on the Rights of the Child. Geneva, Office of the United Nations High Commissioner for Human Rights.

Unknown (2009). Stimulus package for Tasmanian manufacturing jobs Manufacturers' Monthly. Online - http://www.manmonthly.com.au/Article/Stimulus-package-forTasmanian-manufacturing-jobs/508021.aspx, Reed Business Information.

Weisbrod, B. A. (1962). "Education and investment in human capital." The Journal of Political Economy 70(5): 106-123.

Wilkins, R. (2004). "The effects of disability on labour force status in Australia." The Australian Economic Review 37(4): 359-382.

World Bank (2008). Official list of MDG indicators. Washington D.C., World Bank.

Zhang, X., X. Zhao, et al. (2006). Chronic illness and labour force partipation in Australia. Australian Health Economics Society Conference. Perth.

\section{Biographical Notes}

Emily Callander is a research associate at the University of Sydney. My research focuses on cross-disciplinary considerations of inequality. She has a background in applied economics that stretches across numerous disciplines including health, environmental and welfare economics.

Deborah Schofield is Chair of Health Economics at the NHMRC Clinical Trials Centre and School of Public Health, University of Sydney. Her career has spanned the Australian Government public service, academia and clinical practice and she enjoys a national and international reputation for her work in economic modelling of the health system

Rupendra Shrestha is a senior research fellow at the NHMRC Clinical Trials Centre, University of Sydney. She specialise in biostatistics, and microsimulation modelling.

Simon Kelly is a director of KELLYresearch and a former Principal Research Fellow at NATSEM. He regularly undertakes consultancy work for NATSEM and is a key member in the development of APPSIM. He has been undertaking NATSEM research for over ten years. His main research interests are population ageing, household wealth and retirement savings. Simon is regarded as the leading Australian microsimulation modeller of household wealth and retirement savings. 